\title{
LAS EXPOSICIONES DE 1929 EN LA PRENSA ESPAÑOLA NO ESPECIALIZADA "TODO ES BELLEZA Y PARADOJA EN ESTE PABELLÓN"
}

\author{
Alberto Ruiz Colmenar \\ Las Exposiciones Universales han albergado a lo largo del siglo XX algunos de los ejemplos más relevantes de arquitectura mo- \\ derna. La atención sobre estos eventos por parte de la prensa generalista ha servido históricamente como vehículo de difusión \\ de la arquitectura moderna. Las exposiciones celebradas en España en 1929 supusieron uno de los primeros ejemplos de este \\ fenómeno de divulgación entre el público no especializado.
}

Palabras clave: Exposiciones universales, prensa no especializada, arquitectura española, crítica, difusión cultural Keywords: Universal Exhibitions, Non-specialized Press, Spanish Architecture, Critics, Cultural Dissemination

\begin{abstract}
"La arquitectura es de todas las artes la que más se resiste al progreso. Estática, anticuada, parece aprisionada bajo las piedras seculares y sin comprensión hacia el presente. La vivienda del hombre de hoy -mecanizadono puede ser la misma de sus antepasados, el hombre guerrero, el hombre místico, el hombre romántico"".
\end{abstract}

El texto que abre este artículo apareció en la edición impresa del periódico $A B C$ en el mes de mayo de 1930. Esta reflexión es parte del análisis que su autor, Francisco Marroquín, hacía del sorprendente pabellón con el que Alemania había participado en la Exposición Universal de Barcelona del año anterior. Este edificio, uno de los iconos de la arquitectura del siglo XX ha sido analizado en multitud de textos clásicos y estudiado en las aulas de todas las escuelas de arquitectura del mundo. Dentro del ámbito especializado hay pocas cosas que no se hayan escrito sobre él. Lo que hace interesante este texto es, precisamente, que está incluido en las páginas de un medio generalista y dedicado a público no especializado. Se pretende en este artículo analizar, de forma somera, un ejemplo de la repercusión que la arquitectura ha tenido en la prensa diaria, centrándose en dos acontecimientos que generaron interés suficiente para merecer la atención de este medio. Estos eventos, que comparten año y país de celebración, pero se concibieron y desarrollaron con espíritu muy diferente, son las exposiciones de Barcelona y Sevilla, universal una, de ámbito iberoamericano la otra, celebradas en el año 1929. Las fuentes a analizar las aportan las hemerotecas de los dos periódicos decanos de este país, $A B C$ y La Vanguardia.

Por espacio de varios meses, las Exposiciones Universales se utilizan para la autopromoción del organizador, y en ese propósito, la propia selección de la arquitectura de los pabellones supone un instrumento de indudable eficacia. El Crystal Palace de Londres, la Torre Eiffel en París o el Atomium de Bruselas, nacieron con la excusa de servir de albergue a los actos de la Exposición, pero se convirtieron en auténticos iconos una vez finalizado el evento. La temporalidad de la muestra, que a priori podría considerarse un problema, permitía un mayor grado de experimentalidad, y estos edificios, que sin este pretexto difícilmente hubieran sido construidos ni aceptados por la sociedad, pasaron a formar parte del imaginario urbano $-\mathrm{y}$, en cierto modo, sentimental- de las ciudades organizadoras. Esta particular característica de los pabellones acerca su arquitectura al público general, que entra con facilidad en el debate sobre la idoneidad del mismo, tomando partido -bien a favor o en contra- con argumentos que pocas veces tienen que ver con la calidad del edificio. $\mathrm{O}$ al menos con lo que los arquitectos entendemos por 'calidad' cuando hablamos de arquitectura. El ejemplo más evidente de esta circunstancia lo constituye la construcción de la Torre Eiffel en la Exposición Universal de 1889, polémica desde su concepción y que con los años se ha convertido en el elemento urbano más característico de la ciudad de París. Respecto a su difusión entre este público general, merece la pena analizar alguna crónica que, al respecto, se publicó en la prensa española. En este caso en La Vanguardia en su edición del 1 de noviembre de 1890, firmado por J. L. Pellicer.

1. MARROQUIN, Francisco, "El pabellón de Alemania en la Exposición de Barcelona. Hacia una nueva arquitectura", en $A B C, 26$ de enero de 1930, pp. 13 y 14 


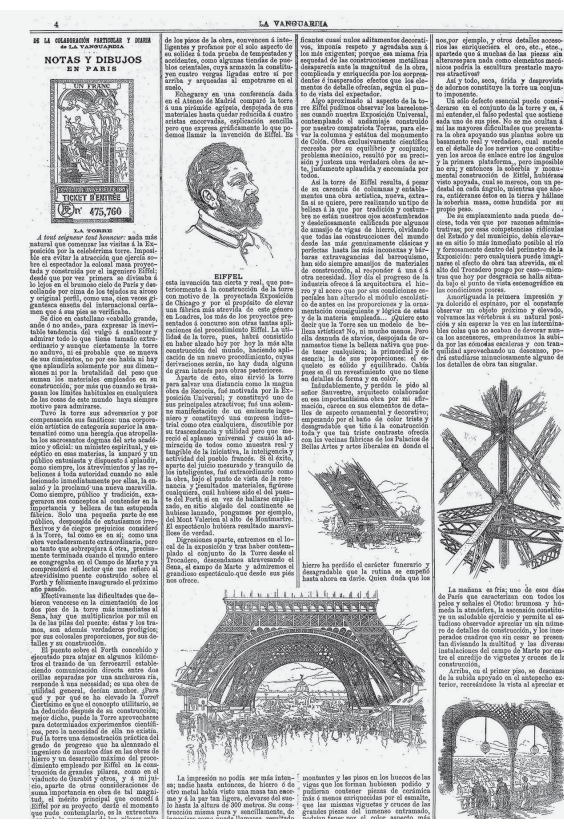

1

2. PELLICER, J.L., "Notas y dibujos en París. La Torre", en La Vanguardia, 1 de noviembre de 1890

3. "Varios aspectos de la genial y maravillosa Plaza de España", en $A B C, 5$ de mayo de 1929 , p. 3

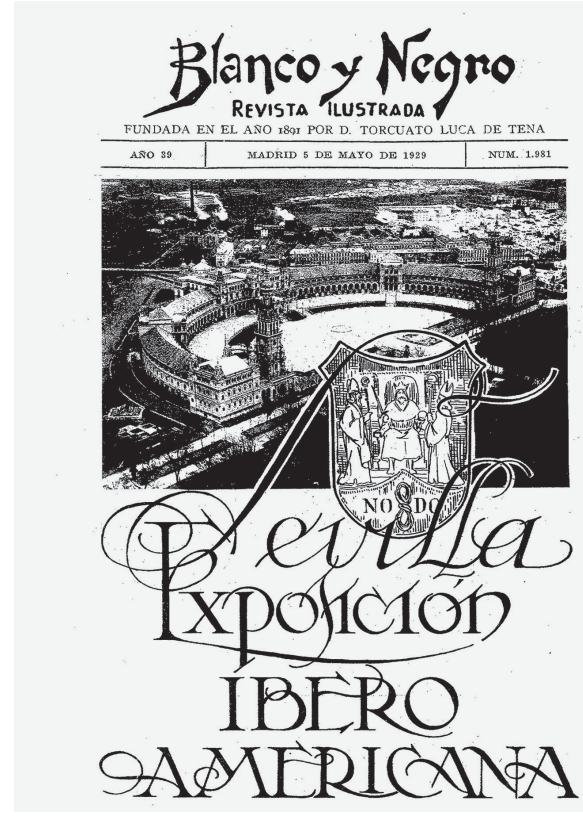

2

\begin{abstract}
"Tuvo la torre sus adversarios y por compensación sus fanáticos; una corporación artística de carácter superior la anatematizó como una heregía (sic) que atropellaba los sacrosantos dogmas del arte académico y oficial; un ministro espiritual, y escéptico en esas materias, la amparó y un público entusiasta y dispuesto a aplaudir, como siempre, los atrevimientos y las rebeliones a toda autoridad, cuando no sale lesionado inmediatamente por ellas, la ensalzó y la proclamó una nueva maravilla"2.
\end{abstract}

El artículo continuaba a lo largo de dos páginas desgranando las características de la torre en un lenguaje sencillo y de fácil comprensión - no olvidemos cuál era su público objetivopero que permite hacerse una idea clara de la impresión que el edificio produjo en el redactor y que éste transmitió a unos lectores que en su gran mayoría jamás tendrían la oportunidad de visitar el monumento. Otra característica interesante de este artículo, costumbre habitual en $A B C$, es la inclusión de dibujos explicativos de corte técnico, como el correspondiente a los nudos estructurales o el desarrollo de una de las escaleras (Fig. 1).

Este breve compendio de historias de arquitectura comienza con la celebración, en 1929, de los primeros eventos de cierta categoría celebrados en España: la Exposición Universal de Barcelona y la Iberoamericana de Sevilla. Como no podía ser de otra forma, $A B C$ planteó un considerable despliegue informativo de ambos acontecimientos, destacando los números especiales editados el 5 de mayo, para la Exposición sevillana -con 30 páginas dedicadas al evento (Fig. 2)- y el 19 de mayo para la celebrada en Barcelona -34 páginas (Fig. 3)-. No toda la información incluida en estos números tiene que ver con la arquitectura de sus pabellones aunque, de una u otra manera está presente de forma continuada en ambos reportajes.

Respecto a la Exposición sevillana, en la edición diaria de $A B C$ se presenta una breve reseña de algunos de sus lugares más significativos, comenzando por la Plaza de España (Fig. 4) y siguiendo por los pabellones de la República Argentina, Estados Unidos, Méjico, Brasil y Portugal y el de Cuba y República Dominicana. También aparecen los de las regiones españolas y los edificios más genéricos -Pabellón Real, Casino y Teatro, Pabellón de agricultura y Palacio de Bellas Artes. Los titulares de los artículos dejan poco lugar a dudas respecto al posicionamiento del periódico acerca de los edificios: "Varios aspectos de la genial y maravillosa Plaza de España" (Fig. 5), "La instalación de los Estados Unidos, que por su arte, figura entre las primeras" o "Dos hermosos pabellones de pueblos a quien España considera como hermanos". Se puede comprobar que estos artículos se destinan a la alabanza, un tanto desmesurada, de la calidad de la Exposición.

"Cuanto pudiera decirse en elogio y loa de la soberbia obra resultaría siempre pálido y pobre ante la realidad de esta estupenda traza, de la maravillosa ejecución, de los mil detalles, primores y filigranas de todo género que la decoran y realzan. La Plaza de España es la corona y el remate de esta pasmosa obra de la Exposición”3. 


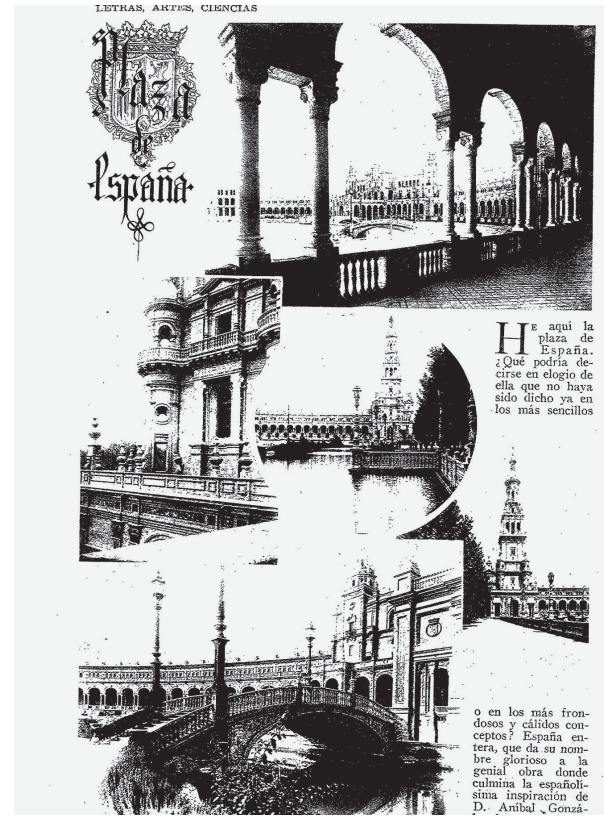

4

Si profundizamos en el análisis de la imagen del arquitecto, resulta este un caso paradigmático de la consideración que se tenía hacia la labor del técnico. Se cita el nombre del autor de prácticamente todas las obras reseñadas -Martín Noel en el pabellón argentino, William Templeton Johnson en el de Estados Unidos, o González Rojas, Durán Loriga y Pérez Carasa en los regionales-, arquitectos de no demasiado renombre pero a los que se consideraba merecedores de reconocimiento. Mención aparte merece la figura de Aníbal Álvarez, arquitecto jefe de la Exposición al que, no solo se hace referencia de forma recurrente, sino que es protagonista de un artículo específico.

"Esta es, a grandes rasgos, la personalidad eminente del hombre que, al crear con su genio de artista y de hombre de ciencia el recinto del gran Certamen iberoamericano, en lo que atañe a España, aporta a nuestro blasón de cultura un glorioso prestigio más ante la mirada contemplativa y, de seguro, admiradora del mundo"4 (Fig. 6)

De aquí en adelante, la cobertura de otras exposiciones de similar interés derivaría progresivamente en análisis más críticos y en la omisión generalizada, asunto curioso, del nombre de los autores de los pabellones. En lo que respecta al semanario Blanco y Negro, la cobertura es muy similar, incluyendo la reseña de algunos de los pabellones a los que no se hacía referencia en el diario -Perú, Chile, Uruguay, Colombia- y ampliando la que se aportaba de los más importantes. Más allá de la descripción de los edificios, merece la pena destacar la profusión de información gráfica de los mismos y la constante referencia a sus autores.

Cuando unos días después, se inauguraba la Exposición Universal en Barcelona, el despliegue de ambas cabeceras fue igual de importante. Aparecen artículos tanto en la edición diaria de $A B C$ como en el semanario Blanco y Negro, con un esquema muy similar a los dedicados a la muestra sevillana en los que se glosaba la arquitectura de los pabellones. La diferencia fundamental viene por su mayor componente polémica. A lo largo del año 1929 y ya entrado 1930 aparecen varios artículos que, sin ser críticos en exceso, sí plantean aspectos de un calado algo más profundo. Se ponen sobre la mesa cuestiones relativas a la historia de las exposiciones Universales ${ }^{5}$ y, sobre todo, a la importancia de estas para la maltrecha autoestima de un país que aún no terminaba de recuperarse de los reveses sufridos a finales del siglo anterior.

"Los turistas extranjeros no vuelven de su asombro y se muestran aún más entusiastas que nosotros. No creían posible tal milagro de este lado de los Pirineos. Un financiero belga, que conoce bien Europa, me decía en el hotel: "Da vergüenza oír las cosas que se oyen fuera de aquí, sobre España, cuando se ha visto esto. ¡Es una maravilla! Lo que sucede es que ustedes los españoles son demasiado modestos cuando hablan de sus cosas, y los demás países, hasta los que presumen de más cultos, ignoran por completo lo que ha sido España y lo que es hoy día"Y yo asentía orgulloso, sabiendo que esas palabras no eran vagos cumplidos de viajero amable, sino que responden a la realidad"6 (Fig. 7).

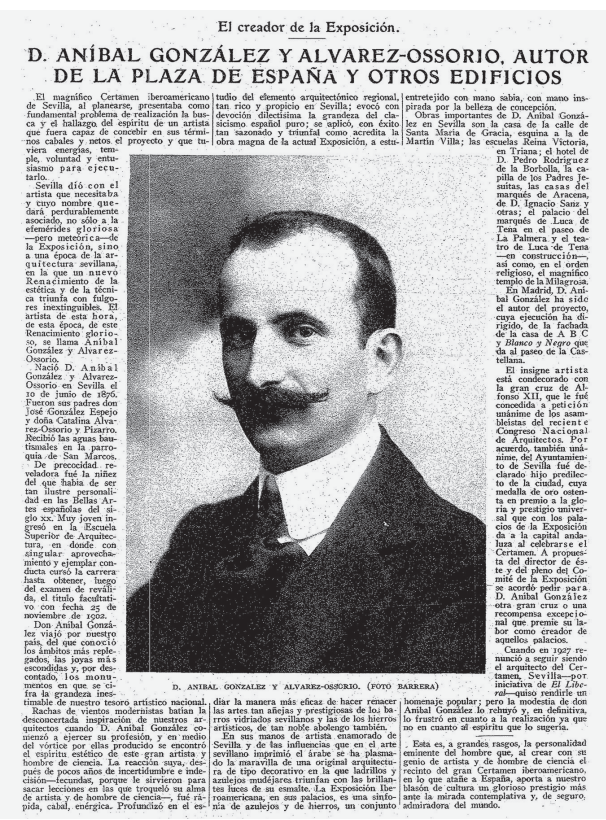

6

Fig. 1. La Vanguardia. 1 de noviembre de 1890. Fig. 2. Blanco y Negro. Primera página del 5 de mayo de 1929. Fig. 3. ABC. Primera página del 19 de mayo de 1929. Fig. 4. Blanco y Negro. 5 de mayo de 1929, p. 20. Fig. 5. $A B C .5$ de mayo de 1929, p. 3 Fig. 6. $A B C .1929,5$ de mayo, p. 5
4. "D. Aníbal González y Álvarez-Ossorio, autor de la Plaza de España y otros edificios", en $A B C, 5$ de mayo de 1929, p. 5. 5. BERMÚDEZ CAÑETE, Antonio, "Lo particular de las Exposiciones Universales. Un poco de historia", en Blanco y Negro, 16 de junio de 1929, pp. 4 a 8.

6. ALCALÁ-GALIANO, Álvaro, "Barcelona y su Exposición. La reina del Mediterráneo", en ABC, 2 de noviembre de 1929, pp. 7 y 8. 


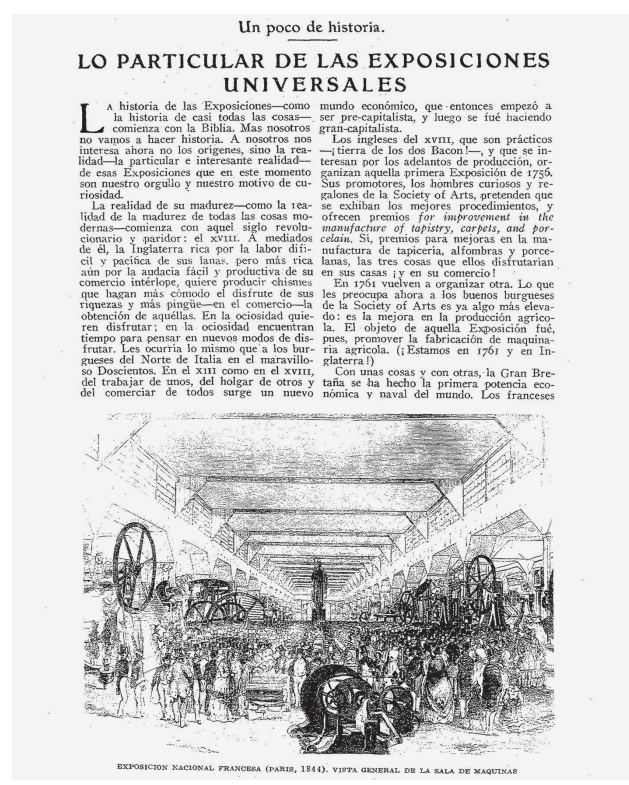

7

Fig. 7. Blanco y Negro. 26 de junio de 1929, p. 4. Fig. 8. $A B C .26$ de enero de 1930, pp. 13 y 14.

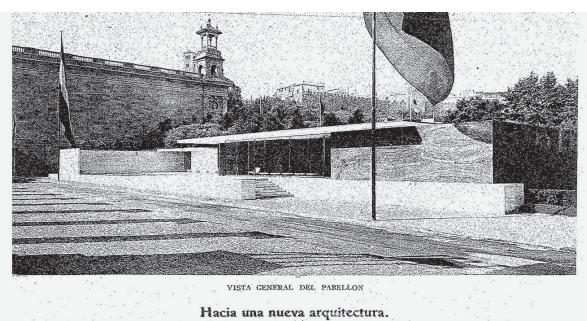

EL PABELLÓN DE ALEMANIA EN LA EXPOSICIÓN DE BARCELONA
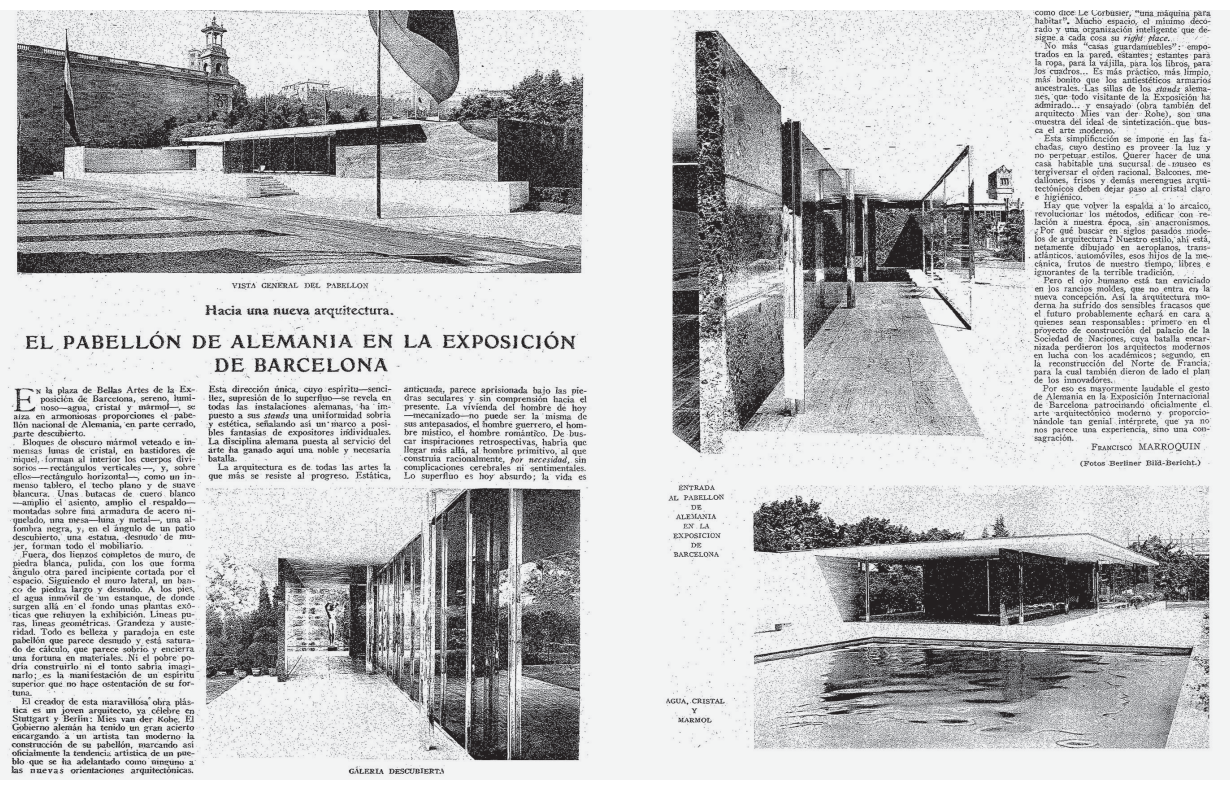

8

España estaba necesitada de reconocimiento, interno y externo, y estos dos eventos supusieron una demostración de que el nivel organizativo -y la calidad del producto mostradoestaba a la altura del que podían desarrollar las naciones más avanzadas. Todo ello pese a que gran parte de la organización expositiva, particularmente en lo referente a la parte industrial de la muestra barcelonesa, estaba a cargo de Alemania, que se encargó de la construcción de dos pabellones de nueva planta y de "instalaciones en 10 palacios de la Exposición. La superficie total que ocupan es de 16.000 metros cuadrados"7. Teniendo en cuenta este hecho, produce cierta sorpresa la casi nula aparición de la figura de Mies van der Rohe -y por descontado, de Lilly Reich- en la cobertura mediática por parte de los periódicos españoles. Más aún si consideramos el impacto que a buen seguro debió tener el pabellón alemán. En una muestra donde gran parte de los elogios se dedican a la construcción del Pueblo Español $^{8}$ sería de esperar que el aspecto casi revolucionario para la época del edificio de Mies supusiera una cuestión, si no polémica, al menos reseñable.

Muy al contrario, en todo el año 1929 las referencias al mismo se limitan a un artículo breve sin firma publicado el día 28 de mayo con motivo de su inauguración, en el que básicamente se relata la visita de los Reyes de España al pabellón acompañados de las autoridades alemanas y del propio arquitecto y a la descripción que realiza Buenaventura Bassegoda junto a la de otros pabellones extranjeros que se tratará más adelante. Existe abundante material gráfico acerca de la visita Real, publicado en monografías sobre el pabellón y sobre la obra de Mies van der Rohe, aunque la prensa no aportó ninguna imagen reseñable.

La hipótesis aceptada de forma general a este respecto parte de una premisa: que las figuras más reconocidas por la crítica especializada fueron, salvo casos muy puntuales, desconocidas, cuando no ignoradas, a nivel de prensa general. Sin embargo, un estudio pormenorizado de los artículos incluidos en esta investigación arroja resultados contradictorios. Valga como ejemplo, dejando por un momento de lado las Exposiciones del año 1929, el aparecido en La Vanguardia con fecha 17 de junio de 1931, firmado por el periodista Felipe Fernández Armesto, con su seudónimo habitual, Augusto Assía titulado «Exposición Universal de Arquitectura”.

"Esta Exposición es, indudablemente, la síntesis más completa y acabada del magnífico fenómeno de la arquitectura actual. En ella se conjugan, por primera vez, todas las modalidades de este fenómeno, en las cuales puede sorprenderse cómo las características de cada país han ido conformando y dándole acento propio a una idea abstracta e internacional, como es la que preside la creación de la nueva arquitectura.

En uno de los pabellones han sido construidas 24 viviendas modelo, perfectamente aparejadas y rematadas. El pabellón ofrece el aspecto de un completo barrio; el arquitecto Mies van der Rohe ha construido auténticas casas que se levantan sobre un jardín, haciendo la ciudad un cuerpo orgánico con él. Es decir, las casas pertenecen tan directamente al jardín como los árboles o las mismas flores" 9 .
7. "Solemne inauguración de los pabellones de Alemania", en $A B C, 28$ de mayo de 1929, p. 24.

8. "El pueblo típico español, uno de los mayores aciertos de certamen barcelonés", en $A B C, 19$ de mayo de 1929, pp. 15-19.

9. ASsíA, Augusto, "Exposición universal de Arquitectura. Crónicas de Berlín”, en La Vanguardia, 17 de junio de 1931, p. 5. 
Lo más reseñable de esta pieza es, probablemente, la peculiar interpretación del autor acerca de la condición orgánica de la arquitectura de Mies, tan alejada de la concepción canónica sobre su obra. Independientemente de lo acertado o no de este análisis en clave de integración paisajística volvemos a encontrar un artículo en el que una obra de arquitectura se analiza más allá de cuestiones circunstanciales. Valga reseñar que en un análisis detallado de la difusión de temas de arquitectura en prensa ampliado a años posteriores no son infrecuentes las referencias a arquitectos de vanguardia como Walter Gropius, Mies van der Rohe o a figuras del panorama nacional como Miguel Fisac, Carlos Arniches y Martín Domínguez o Luis Gutiérrez Soto. Parece claro que la figura de Mies resulta, en esta época, familiar para el lector habitual del periódico, a pesar de la falta de referencias directas en la cobertura de la Exposición. Esta extraña omisión se vio compensada unos meses después, con la publicación del artículo al que hacíamos referencia al comienzo de este texto: "El Pabellón de Alemania en la Exposición de Barcelona", firmado por Francisco Marroquín, con el significativo subtítulo "Hacia una nueva arquitectura" (Fig. 8).

\begin{abstract}
"Líneas puras, líneas geométricas. Grandeza y austeridad. Todo es belleza y paradoja en este pabellón que parece desnudo y está saturado de cálculo, que parece sobrio y encierra una fortuna en materiales. Ni el pobre podría construirlo, ni el tonto sabría imaginarlo; es la manifestación de un espíritu superior que no hace ostentación de su fortuna.

La arquitectura es de todas las artes la que más se resiste al progreso. Estática, anticuada, parece aprisionada bajo las piedras seculares y sin comprensión hacia el presente. La vivienda del hombre de hoy -mecanizadono puede ser la misma de sus antepasados, el hombre guerrero, el hombre místico, el hombre romántico. De buscar inspiraciones retrospectivas, habría que llegar más allá, al hombre primitivo, al que construía racionalmente, por necesidad, sin complicaciones cerebrales ni sentimentales. Lo superfluo de hoy es absurdo; la vida es demasiado precisa; la casa debe ser, como dice Le Corbusier, "una máquina para habitar". Mucho espacio, el mínimo decorado y una organización inteligente que designe a cada cosa su right place"10
\end{abstract}

Merece la pena analizar con mayor detenimiento este texto, ya que demuestra que la arquitectura 'moderna' no se rechazaba de plano, sino que incluso existía una cierta corriente partidaria de abrazar las ideas arquitectónicas que venían de Europa. Es cierto que estos análisis eran puntuales y que la tendencia generalizada era a apreciar más la arquitectura tradicional -en esa misma Exposición, la instalación con mayor afluencia de público y seguimiento mediático fue, sin duda, el Pueblo Español. Sin embargo el interés por las 'tendencias arquitectónicas modernas' -utilizando el título de una serie de artículos firmados por Manuel Abril en aquel mismo año en el suplemento Blanco y Negro-era innegable.

Ciertos conceptos manejados por Marroquín en este artículo merecen mayor atención. Se habla de Le Corbusier, ciertamente conocido incluso por el público no especializado ${ }^{11}$, y sobre todo se introduce una idea, la de la vivienda con "mínimo decorado y una organización inteligente" que ya suponía el núcleo del discurso de Carlos Arniches y Martín Domínguez en sus artículos para el periódico El Sol, publicados unos años antes. Además, menciona una idea importante: la concepción de la arquitectura como 'manifestación de un espíritu superior', concepto que como ya sabemos fue explotado en los años posteriores por regímenes políticos que entendieron que, a través del Arte, era posible controlar la manera de pensar de la población. Debemos tener en cuenta que, en los años previos a la Guerra Mundial, existía en Europa cierta condescencia, cuando no abierta simpatía, por los movimientos totalitarios que empezaban a surgir en Alemania. La deriva posterior del régimen nazi demostró lo equivocado de este planteamiento, pero en los primeros años de la década de 1930 podemos encontrar artículos como este de César González Ruano, corresponsal de $A B C$ en Alemania, llamado "El Día de Hitler", que traemos a colación por alguna curiosa referencia a las aficiones arquitectónicas del mandatario alemán.

"De pronto, mira el reloj. Se hace un silencio en torno a un posible quehacer nacional. Es que Hitler ha prometido bajar al pueblo para dictaminar sobre unas obras. Conviene no ignorar esto: el albañil Hitler está muy enterado de arquitectura. Él fue, en realidad, el principal arquitecto de la Casa Parda de Munich, la casa central del partido nacional-socialista. Él ha sido también el arquitecto de la nueva Alemania"12 (Fig. 9).

En este tipo de textos encontramos el germen de las ideas de recuperación de las tradiciones a las que se adscribió la nueva arquitectura nacional que surgió de las ruinas de la contienda civil en España. Si analizamos la deriva de los temas aparecidos en Prensa, podemos ver cómo el incipiente interés por la arquitectura vanguardista importada de Europa desapareció -abruptamente en algunos casos- para ser sustituida por la versión oficial de lo
10. MARROQUIN, Francisco, op. cit. Francisco Marroquín es, dentro de los periodistas que, en mayor o menor medida, se han dedicado a temas de arquitectura uno de los menos conocidos. Su labor dentro de las páginas de $A B C$ y $B l a n c o$ y Negro se dedicó fundamentalmente a la crítica de teatro y cine, por lo que se puede considerar el artículo referido como una magnífica excepción. Esta reseña demuestra, en cualquier caso, el amplio interés que el pabellón generó incluso entre los críticos no especializados en arquitectura.

11. Le Corbusier era, sin ningún género de dudas, el arquitecto extranjero más conocido en la España de la época. Y esto se debe, entre otras cosas a su habitual presencia en las páginas de la prensa diaria. En cualquier caso, su característico sesgo polémico no le abandonó ni siquiera en estas circunstancias. Desviándonos puntualmente del tema de este artículo resulta interesante citar la disparidad de opiniones que suscitaba incluso entre sus propios colegas. Mientras Fernando García Mercadal afirmaba "Le Corbusier-Saugnier pertenece al grupo de los inadaptados, de los que sienten el imperioso deseo de contribuir a la creación de una nueva arquitectura" (La arquitectura moderna en Francia. Le Corbusier-Saugnier. El Sol. 24 de enero de 1925), su compañero Luis Lacasa sostenía una visión mucho menos idealizada del suizo: "No nos ocuparíamos tanto de Le Corbusier, que en sí no tiene ninguna importancia, sino porque dos circunstancias dan a su personalidad un relieve momentáneo: la primera, que Le Corbusier es un activo representante de una teoría incorrecta; la segunda, que en España ha tenido cordial y extensa aceptación entre los intelectuales". (Le Corbusier 0 Américo Vespucio. El Sol. 26 de julio de 1928). A este respecto, resultan imprescindibles las investigaciones de Ángel Isac, entre las que podemos citar "Eso no es arquitectura.": Le Corbusier y la crítica adversa en España (1923-1935)", publicada por el Centre de Cultura Contemporània (Barcelona, 1987) y por supuesto su Tesis Doctoral "Eclecticismo y Pensamiento Arquitectónico en España. Discursos, Revistas, Congresos. 1846-1919" que dedica un capítulo completo al 'periodismo arquitectónico'.

12. GONZÁLEZ RUANO, César, "El día de Hitler", en $A B C, 18$ de agosto de 1933, pp. 8 y 9 . Hay pocos autores de la época más controvertidos que González Ruano. Su oscura biografía, que incluye una tormentosa relación con el régimen nazi pero también un estrecho vínculo con la vanguardia artística del París ocupado no puede ocultar su magnífica altura en lo que Francisco Umbral definía como "el viejo periodismo español, valedero y necesario como los viejos vinos" (El viejo periodismo. El País. 10 de enero de 1982). 


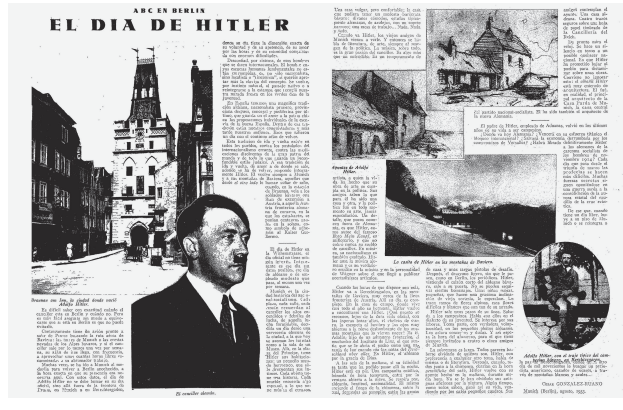

Fig. 9. $A B C .18$ de agosto de 1933, pp. 8 y 9. que debía ser el arte español impuesta desde el régimen franquista. Ideas como la condena del 'arte degenerado' -término heredado directamente de la terminología nazi- o la reivindicación de los valores tradicionales a través de la arquitectura herreriana se convertirían en una línea editorial constante que tardaría en ser superada.

Resulta indudable que las exposiciones de Sevilla y Barcelona tuvieron una repercusión importante en la prensa española. Ambas muestras supusieron un motivo de orgullo para el país y una importante carta de presentación respecto al resto de naciones implicadas en los eventos. Por otra parte, la arquitectura que proponían sus pabellones era apreciada -incluso ejemplos tan aparentemente anacrónicos como el pabellón alemán- y sus autores puestos en valor. Es habitual considerar el edificio de Mies como un elemento extraño, ajeno al resto de la arquitectura de la Exposición y por ende, asumir que esto provocara el rechazo de la sociedad. Sin embargo, tomando como referencia su análisis en prensa -análisis que, no olvidemos, estaba al alcance del público no especializado- podemos aventurarnos a afirmar que, si bien resulta evidente que se trataba de una propuesta poco convencional, su diseño no resultó tan polémico como se podría pensar en un principio.

Pero hay más arquitectura en las Exposiciones de 1929. Es obvio que el resto de pabellones no tuvieron ni la importancia ni la repercusión del alemán pero la cobertura en Prensa de ambas alcanza un ámbito mayor. A este respecto merece la pena analizar la figura de Buenaventura Bassegoda ${ }^{13}$, autor de una interesante serie de artículos acerca de la Exposición de Barcelona para La Vanguardia, diez en total, entre los meses de mayo y octubre de 1929. Bassegoda era colaborador habitual del periódico, especializado en temas del patrimonio arquitectónico de la ciudad y, algo que resulta reseñable por poco habitual entre los articulistas de la época, era arquitecto. Así, su opinión sobre las exposiciones aportaba una visión particular desde el punto de vista profesional.

Los artículos de Bassegoda son, en general, de corte meramente descriptivo. Relataba, de forma particularmente minuciosa, las características de cada uno de los edificios, citando medidas, materiales y refiriéndose siempre de forma elogiosa - no olvidaba nunca citar su nombre- a los autores de los proyectos. En cualquier caso, y quizá esto sea una impresión puramente personal, en sus textos subyace una intención que va más allá de la mera exposición de datos. Da la sensación de que sus descripciones siempre se guardan algo más, quizá un atisbo de crítica, que refrena de forma elegante: "La modestia, para no usar otro nombre, de los cuatro edificios que sirven de fondo a esa fuente monumental, contribuye a resaltar sus bellezas"14; "Por lo que pude comprender en mi visita, la disposición de los 'stands' no se ha hecho con las líneas de la construcción, a juzgar por las líneas señaladas en el suelo. Mucho me holgara de haberme equivocado"15; “(...) Palacio Meridional, muy bien concebido por nuestro arquitecto Antonio Millás, dentro de las onerosas condiciones de economía que esclavizaron su generoso lápiz"16.

Esta interpretación se ve reforzada por el artículo del 22 de agosto de ese mismo año, titulado "Palacio de Proyecciones" del que se extracta este texto.

\footnotetext{
"Como las notas que vengo publicando referentes a nuestro admirable Certamen Internacional no tienen la pretensión de ser una Guía de forasteros, antes bien ligeros comentarios de carácter criticoartístico, sigo con pausa mis paseos por el Parque de Montjuich con el principal objeto de poner de relieve los méritos de la obra de mis compañeros de profesión. Para una Guía resultarían, en verdad, excesivamente trasnochados; pero como comentario crítico, son necesarios ante la campaña derrotista emprendida en nuestro suelo, en nuestra misma ciudad y, naturalmente, en alguna nación extranjera." ${ }^{17}$.
}

Se entiende ahora mejor esa distanciada sutileza a la hora de criticar los edificios de sus compañeros. Cierto tono corporativista suele ser una constante en los escritos de arquitectos opinando sobre otros arquitectos, aspecto que curiosamente es mucho menos frecuente en otras disciplinas. Seguramente, las páginas de un periódico no son el foro más habitual para ejercer la crítica especializada, pero en ocasiones se echa de menos un espíritu algo más analítico que, sin llegar a la descalificación, permita al lector, incluso al no familiarizado con el tema, componer su propio criterio.

En cualquier caso, los artículos que Bassegoda dedicó a la Exposición barcelonesa con su magnífica, aunque algo alambicada prosa nos permiten tener una descripción detallada 
de los pabellones y del ambiente general de la muestra, a pesar de la falta de información gráfica de la que en general adolece la cobertura dedicada al evento por parte de La Vanguardia. Valga como ejemplo el texto referente al pabellón de Yugoslavia, una de las obras más interesantes aunque poco conocidas de la muestra:

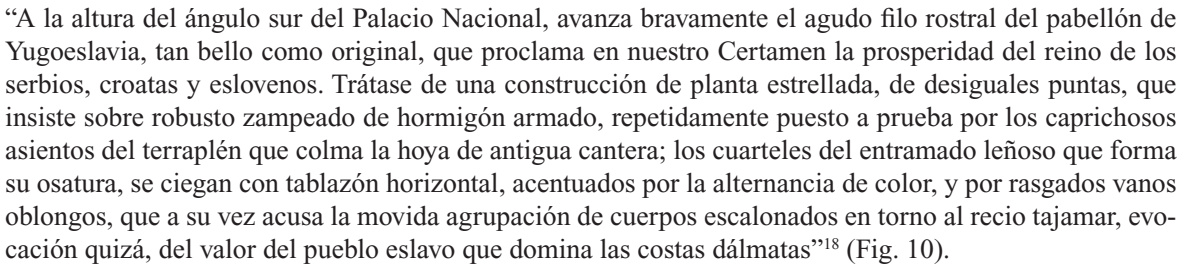

Este artículo refuerza la idea de que el lenguaje poético aunque un tanto confuso que nos caracteriza -quizá más a menudo de lo recomendable- a los arquitectos no es exclusivo de nuestros tiempos. Las fotografías de la Exposición se limitaron en la práctica a algunas imágenes descontextualizadas aparecidas en el suplemento Noticiero Gráfico que, en general, se dedicaban a noticias de sociedad. Es cierto que La Vanguardia no poseía el componente de diario gráfico que si tenía -y aun tiene- $A B C$, así que las excepcionales descripciones de sus cronistas se convirtieron en la mejor manera de dibujar la Exposición a sus lectores.

Bassegoda dedica dos artículos a los Pabellones extranjeros, los días 18 y 31 de octubre. Además del pabellón de Yugoslavia, describe entre otros el pabellón belga, el sueco, el danés y, por supuesto, el alemán, del que dice:

"Si ante la genial creación del eminente arquitecto Mies van der Rohe queda atónito algún que otro espectador liviano, y llega a preguntarse si se halla frente a una construcción inacabada, todo espíritu culto y despierto se inclina con admiración o con respeto, al comprender la significación de una lucha ardua y tenaz por librarse de la tutela de convencionalismos artísticos y de la férula de las formas consagradas, a fin de poder manifestar (...) 'el ardiente deseo de la Alemania moderna de caracterizarse por su claridad, sencillez y sinceridad" 19 (Fig. 11).

Resulta indudable que gran parte de este interés mediático se deriva directamente del carácter local de ambas exposiciones. Como decimos, ambas sirvieron de escaparate internacional de un país que había quedado retrasado en la evolución científica y cultural respecto a las potencias más involucradas en la Revolución Industrial. Una vez que la apuesta colonial fracasó, la posición de España en el concierto internacional, a pesar de su posición neutral en la Gran Guerra, había quedado muy afectada.

En las crónicas de ambas exposiciones subyace en cierto modo este complejo de inferioridad que lleva a valorar lo construido por la imagen que proyecta al extranjero casi más que por su auténtico valor. Lo cierto es que más allá del tono autocomplaciente de algunos planteamientos, existía una corriente que entendía que las exposiciones, particularmente la barcelonesa, no podían ser un acontecimiento fugaz sino que debían ser aprovechadas en beneficio de la ciudad. A este respecto, citamos dos artículos. El primero, aparecido en La Vanguardia el día 5 de enero de 1930 y titulado "La utilización ulterior de las instalaciones y servicios de la Exposición" que desgrana los planes de reutilización de las instalaciones de la Exposición de Sevilla y, el segundo, mucho más interesante por su carácter crítico, firmado en el mismo periódico por Santiago Vinardell, titulado "Ciudad ascendente":

"Conviene, creo yo, que esto se diga y se repita en Barcelona. No tanto para que los barceloneses se envanezcan como para que perseveren. Todo eso, que está bastante bien, no puede quedar así. Necesita una continuación. Barcelona acaba de adquirir fama Universal. Sus hombres -los que la rigen hoy y los que la regirán mañana- verán lo que hacen. (...) Barcelona está presentable. La urbanización completa a que aludió el alcalde ha de seguir - con estos y con los otros- hasta el final. (...) Barcelona puede ser - debe serHamburgo. Conforme. Pero Niza también. No todo ha de quedar reducido a zona franca. Cabe muy bien una zona de placer. A base del mar, es claro. Del mar, al que Barcelona ha vivido de espaldas hasta que las nuevas generaciones han iniciado en la Escollera de Levante su reconquista y la Exposición ha encarado con él a los barceloneses desde el incomparable mirador de Miramar"20

Unos meses antes de la publicación de estos artículos, Mariano Rubió y Bellvé ${ }^{21}$ proponía criterios sensatos de reutilización para el parque de Montjuich $^{22}$. Criterios que, si bien no

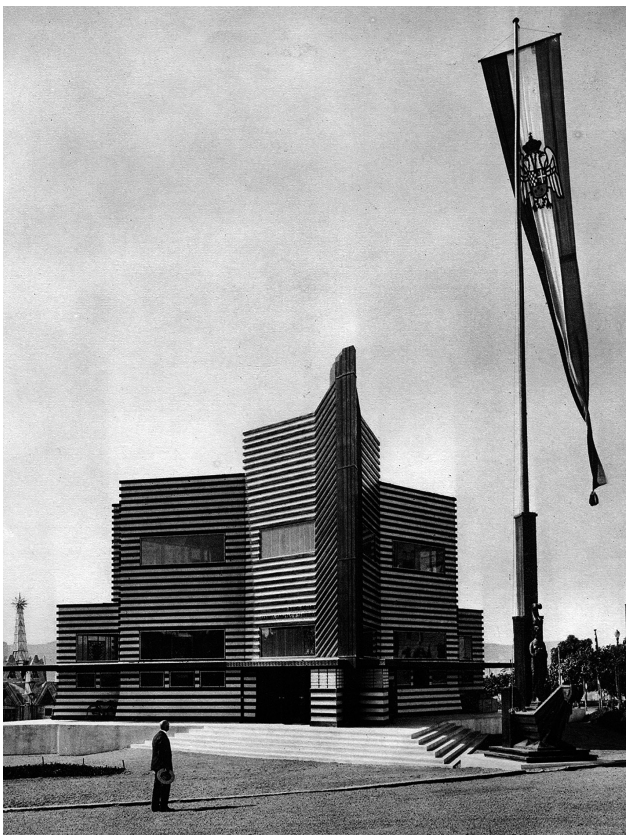

Fig. 10. Pabellón de Yugoslavia en la Exposición Universal de Barcelona. Fuente: Exposición Internacional de Barcelona: 1929. Concesiones Gráficas, Barcelona, 1929.

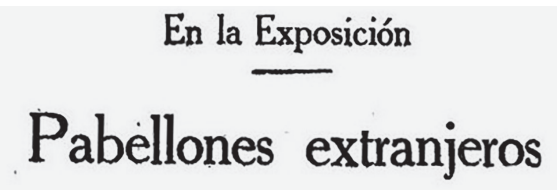

Deseo dedicar, en estas ligeras crónicas, un lugar preferente a los Pabellones de los Estados europeos que oficialmente han querido contribuir al éxito, ya indubitable, de nuestro gran Certamen. Y más por un deber de justicia que de mera cortesía, puesto que su noble conducta ha servido para contrarrestar la de quienes, tal vez a la hora presente, yen cuán equivocados estuvieron. Lamento, con todo, que he de luchar, como siempre, con la falta de espacio.

Muchas naciones europeas figuran con secciones especialles en los diversos palacios que albergan las manifestaciones arcísticas $\theta$ industriales de la Exposición; pero algunas han construído su pabellón oficial con todo el genuino carácter que las distingue unas de otras.

Así, dando frente a la Avenida del Estadio, junto al Paseo Olímpico, surge is masa blanca y tranquila del Pabellón lenoso de Suecia, país de bosques, y la culta

Fig. 11. La Vanguardia. 18 de octubre de 1929, p. 5.

18. BASSEGODA, B., "Más pabellones extranjeros", op. cit. 19. BASSEGODA, B., "Pabellones extranjeros", en La Vanguardia. 1929, 18 de octubre de 1929, p. 5.

20. VINARDELL, Santiago. "Ciudad ascendente", en La Vanguardia, 10 de enero de 1930, p. 5.

21. Otra muestra más de la vocación interdisciplinar de la arquitectura es que Rubió, director técnico de la Exposición de Barcelona tenía formación como ingeniero militar.

22. RUBIÓ Y BELLVÉ, Santiago, "La Tecnoteca de Montjuich", en La Vanguardia, 18 de octubre de 1929, p. 5. 
al cien por cien, se siguieron a la hora de conservar algunos de los elementos más reconocibles de la Exposición -el Estadio, el Palacio Nacional o el Pueblo Español.

La reutilización de las instalaciones, los criterios de conservación de determinadas construcciones y sobre todo, el impacto urbanístico que produce en la ciudad son temas que, más allá de agotarse, han supuesto el núcleo central de análisis de muchos de los eventos que se han celebrado a lo largo del siglo XX. Los pabellones de Exposición son, por definición, efímeros. Sin embargo, y ahí están los ejemplos de la Torre Eiffel o el Atomium, algunas construcciones han acabado por convertirse - a veces involuntariamente- en iconos. En estos casos no existe ya discusión sobre su conservación. Sin embargo, la desaparición de edificios como el propio pabellón alemán -concebido, insistimos, como temporal- arrastró la polémica hasta que se tomó la decisión de reconstruirlo de forma mimética ya en la década de 1980. Peor suerte corrieron otros ejemplos, como el pabellón español diseñado por José Antonio Corrales y Ramón Vázquez Molezún para la Exposición celebrada en Bruselas en 1958, abandonado en un solar perdido de la Casa de Campo madrileña y eternamente propuesto para usos variopintos o la obra de Javier Carvajal para Nueva York en 1964, donado a la ciudad de Saint Louis para su reutilización tras el certamen y que, una vez demostrada la inviabilidad económica de la idea terminó siendo adosado al vestíbulo de un hotel.

En general, se coincide en que una de las mejores decisiones relativas a la celebración de los Juegos Olímpicos de Barcelona en 1992 fue, precisamente, la concepción del evento como un motor de impulso económico y urbanístico para la ciudad. La reutilización de sus instalaciones -particularmente de la Villa Olímpica- es un ejemplo de este planteamiento pero por encima de todo, la decisión consciente de incorporar la salida al mar a la trama urbana de la ciudad supuso el gran acierto de la organización. Ese "abrir la ciudad al mar" que ya reclamaba Santiago Vinardell en 1930. En el planteamiento contrario aunque en las mismas fechas, podemos citar el ejemplo de la Exposición de Sevilla y el complicado proceso de reutilización de los espacios expositivos de la Isla de la Cartuja.

Es posible que las exposiciones que se celebraron en España en 1929 hubieran tenido una repercusión mínima en el panorama de la historia de la arquitectura de no haber sido por el pabellón alemán de Mies. Sin embargo, resultaron ser acontecimientos lo suficientemente interesantes como para merecer la atención de la prensa generalista y, por tanto, llegar a conocimiento del público no especializado. A través de sus páginas, los españoles pudieron asomarse por un momento a una arquitectura muy alejada de la que, a pesar de los esfuerzos de algunos jóvenes arquitectos, se desarrollaba en nuestro país. Es discutible, eso sí, que esta breve mirada tuviera una repercusión real en los gustos arquitectónicos de una población que, en cualquier caso, no tuvo la oportunidad de asistir a la evolución de estas tendencias, cercenadas por el conflicto de 1936 y que tardarían años en volver a plantearse. La apertura a la modernidad viviría otro momento decisivo, eso sí, en otra Exposición Universal, gracias al pabellón que José Antonio Corrales y Ramón Vázquez Molezún diseñaron para la celebrada en Bruselas en 1958.

Pero esa es otra historia.

Alberto Ruiz Colmenar. Universidad Politécnica de Madrid. Arquitecto por la Escuela Técnica Superior de Arquitectura de Madrid (2001). Máster en Análisis, Teoría e Historia de la Arquitectura por la Escuela Técnica Superior de Arquitectura de Madrid (2013). Tesis doctoral en progreso en la Escuela Técnica Superior de Arquitectura de Madrid (UPM) con el título "Arquitectura para no arquitectos. La arquitectura en la prensa española a través de ABC y La Vanguardia: 1929-1965”. Desde 2012, profesor en el Grado en Fundamentos de la Arquitectura de la Universidad Rey Juan Carlos de Madrid. 